\title{
Genetic aetiology of primary adrenal insufficiency in Chinese children
}

\author{
Zhuo Chang, Wei Lu, Zhuhui Zhao, Li Xi, Xiaojing Li, Rong Ye, Jinwen Ni, Zhou Pei, Miaoying Zhang, \\ Ruoqian Cheng, Zhangqian Zheng, Chengjun Sun, Jing Wu and Feihong Luo* (i)
}

\begin{abstract}
Background: Primary adrenal insufficiency (PAI) is life-threatening, and a definitive aetiological diagnosis is essential for management and prognostication. We conducted this study to investigate the genetic aetiologies of PAl in South China and explore their clinical features.

Methods: Seventy children were enrolled in this cross-sectional study. Clinical information was collected, and combined genetic tests were performed according to the children's manifestations. Statistical analysis was performed among the different groups. In silico or in vitro experiments were applied to determine the pathogenicity of novel variants.

Results: Among the 70 children, 84.3\% (59/70) were diagnosed with congenital adrenal hyperplasia (CAH), and 21 -hydroxylase deficiency (21-OHD) was genetically confirmed in $91.5 \%$ of these cases. Salt wasting (SW), simple virilization (SV), and non-classic (NC) CAH accounted for 66.1\% (39/59), 30.5\% (18/59), and 3.4\% (2/59) of the cases, respectively. The 17-hydroxyprogesterone (17-OHP) and testosterone (TES) levels were significantly higher in children with SW than with SV. The 17-OHP and cortisol levels in female SW patients were significantly higher than those in males. The 17-OHP, cortisol, dehydroepiandrosterone (DHEAS) and TES levels in female SW patients were significantly higher than those in female SV patients. Additionally, 72.7\% (8/11) of uncharacterized PAl patients had positive genetic findings. Among all the patients, two novel variants in the CYP21A2 gene (c.833dupT and c.651 + 2T > G) were found. A microdeletion (Xp21.2-21.3) and five novel variants, including 2 in the NROB1 gene (c.323-324CG > GA and c.1231_1234delCTCA), 2 in the AAAS gene (c.399+1G > A and c.250delT) and 1 in the NNT gene (c.2274delT), were detected. The novel variant c.399+1G>A in the AAAS gene was further confirmed to lead to exon 4 skipping during mRNA transcription and produce a truncated ALADIN protein.
\end{abstract}

Conclusions: We found ethnicity-based differences in the CYP21A2 gene variant spectrum among different study populations. Female 21-OHD patients tended to have higher 17-OHP and TES levels, which warrants caution in relation to the effects of virilization. Novel gene variants detected in the CYP21A2, NROB1, AAAS and NNT genes expanded the genetic spectrum of PAl, however, further improvement of genetic testing tools beyond our protocol are still needed to uncover the complete aetiology of PAl in children.

Keywords: Primary adrenal insufficiency, Genetic diagnosis, Whole-exome sequencing, Congenital adrenal hyperplasia, Triple A syndrome, X-linked adrenoleukodystrophy

*Correspondence: luofh@fudan.edu.cn

Department of Pediatric Endocrinology and Inherited Metabolic

Diseases, Children's Hospital of Fudan University, 399 Wan Yuan Road,

Shanghai 201102 , People's Republic of China

\section{Background}

Primary adrenal insufficiency (PAI) is an infrequent but critical clinical condition caused by inadequate secretion of steroid hormones, mainly cortisol and/or aldosterone, 
as well as adrenal sex steroids [1]. PAI in children is very different from that in adults, as congenital disorders caused by genetic aberrations are much more frequent [2]. Based on the affected biological process, the aetiology of inherited PAI can be categorized into several groups [3]. The first is impaired steroidogenesis, such as congenital lipoid adrenal hyperplasia caused by mutations in STAR [4] and 21-hydroxylase deficiency caused by CYP21A2 [5]. This group includes different abnormalities in the steps of steroid biosynthesis. Congenital adrenal hyperplasia $(\mathrm{CAH})$, which is caused by 21-hydroxylase deficiency, accounts for most paediatric PAI cases, ranging from approximately $70-80 \%$ of cases $[2,3]$. The second group is adrenal hypoplasia, including X-linked adrenal hypoplasia congenita (AHC) caused by NROB1 [6], adrenal hypoplasia caused by steroidogenic factor-1/NR5A1 [6], IMAGe syndrome caused by CDKN1C [7] and MIRAGE syndrome caused by SAMD9 [8]. Patients in this group usually lack all adrenocortical hormones, and some of them may have accompanying symptoms such as intrauterine growth restriction and genital abnormalities. The third is adrenocorticotrophic hormone $(\mathrm{ACTH})$ resistance, including familial glucocorticoid deficiency type 1 caused by $M C 2 R$ [9] and familial glucocorticoid deficiency type 2 caused by MRAP [10]. Children in this group usually have a preserved reninaldosterone axis, and plasma ACTH is often markedly increased despite normal glucocorticoid treatment. Adrenal destruction constitutes another group, consisting of Allgrove syndrome caused by $A A A S$ [11], nicotinamide nucleotide transhydrogenase deficiency caused by NNT [12] and thioredoxin reductase deficiency caused by TXNRD2 [13]. The next group is complex lipid metabolism, including X-linked adrenoleukodystrophy (X-ALD) caused by $A B C D 1$ [14], neonatal adrenoleukodystrophy caused by PEX1 [15] and Wolman disease caused by LIPA [16]. The last group is autoimmune destruction, including isolated autoimmune adrenalitis associated with CLTA-4, HLA-DR3, HLA-DR4, HLA-B8 and BACH2 [3].

Among the remaining patients, the aetiology varies greatly based on the study population and test platform. In Asia, Amano et al. [17] applied target gene sequencing and discovered that when excluding 21-hydroxylase deficiency and $3 \beta$-hydroxysteroid dehydrogenase deficiency, genetic defects were detected in $84.7 \%$ of patients, with STAR (32.2\%), NROB1 (30.5\%) and SAMD9 (11.9\%) accounting for the top three. In North America, Tsai et al. [18] used the same method to determine the cause in $81.8 \%$ of patients, and the most common was STAR (45.5\%). In the Middle East, Guran et al. [19] employed a gene panel plus next-generation sequencing and found $81 \%$ positive genetic diagnoses, with $M C 2 R$ (26.3\%), NROB1 (12.6\%) and STAR (11.6\%) as the three most common causes. In Europe, Chan et al. [20] applied whole exome sequencing (WES) and made genetic diagnoses in $41.9 \%$ of patients, with CYP11A1 (14.0\%), NROB1 (9.3\%) and $A A A S(4.7 \%)$ as the most affected genes.

In clinical practice, the differential diagnosis and management of paediatric PAI are quite challenging [21]. Eyal et al. reviewed the epidemiology and risk factors for adrenal crises in children with adrenal insufficiency (AI) between 1990 and 2017 at four Israeli paediatric endocrinology units and found that diagnosis and long-term management of paediatric patients remained a challenge [22]. Adrenal crises are life-threatening emergencies, but studies on the rate and risk factors for adrenal crises in children with AI are scarce [22]. Currently, the exact cause of more than $5 \%$ of paediatric PAI cases is undetermined despite continual detection of novel genetic causes [23]. Considering the limited data for Chinese PAI children, we used multiple molecular testing strategies to explore genetic causes of PAI in Chinese children and to determine the correlation between genotype and phenotype.

\section{Subjects and method Subjects}

Seventy children were diagnosed with PAI from July 2012 to August 2017 at Children's Hospital of Fudan University according to published criteria [24]: (i) initial symptoms suggesting low cortisol levels (e.g., hyperpigmentation, fatigue, failure to thrive, vomiting, electrolyte disturbances); (ii) laboratory examinations indicating high plasma ACTH levels accompanied by low or normal cortisol levels and a less than $500 \mathrm{nmol} / \mathrm{L}$ peak during the ACTH stimulation test; and (iii) availability for genetic testing. All the patients received detailed clinical evaluations, and all female $\mathrm{CAH}$ patients received Prader genital scale (PGS) scores for external genitalia. Patients with hyperkalaemia, hyponatremia, elevated serum 17-hydroxyprogesterone (17-OHP), and external genitalia virilization manifestations were initially suspected of having 21-hydroxylase deficiency (21-OHD), which was further verified through CYP21A2 gene testing [25, 26]. The diagnostic algorithm for PAI patients is shown in Additional file 1: Fig. S1. The study was approved by the Ethics Committee of the Children's Hospital of Fudan University. Written informed consent for the study was obtained from all patients' parents.

\section{Biochemical measurements}

Venous blood samples were drawn at approximately 8 am in the morning, and all hormones were tested within $2 \mathrm{~h}$, including serum ACTH (IMMULITE 2000 ACTH, Siemens, UK), cortisol (Access Cortisol, Beckman Coulter, USA), dehydroepiandrosterone sulphate (DHEA-S; 
Access DHEA-S, Beckman Coulter), testosterone (TES; Access Testosterone, Beckman Coulter) and 17-OHP (17 Alpha-hydroxyprogesterone Radioimmunoassay Kit, Cisbio Bioassays, France).

\section{Molecular analysis}

Genomic DNA was extracted from peripheral lymphocytes, and four genetic tests were performed according to individual clinical presentations: (i) for 59 patients who presented with cortisol deficiency, androgen excess and/or elevated 17-OHP, the CYP21A2 gene was amplified using PCR (Additional file 4: Table S1) and double checked using multiplex ligation-dependent probe amplification (MLPA; SALSA MLPA Probemix, MRC-Holland, Netherlands); (ii) for 2 patients with developmental delay/intellectual disability or congenital anomalies, array-based comparative genomic hybridization (ArrayCGH, Agilent Technologies, CA, USA) was performed; and (iii) the remaining patients underwent WES (SureSelectXT Human All Exon Kit V6, Agilent Technologies, CA, USA).

Variants found in all genetic tests except for Array$\mathrm{CGH}$ were verified by Sanger sequencing in the probands and some of the parents. Truncating variants such as nonsense, frameshift, and splice site variants, gene deletions and previously reported variants were regarded as pathogenic variants. For novel variants with frequencies lower than 0.01 in the ExAC (http://exac.broadinstitute. org/), dbSNP147 (http://www.ncbi.nlm.nih.gov/SNP/) and 1000 Genomes (http://www.internationalgenome. org) databases, pathogenicity was predicted with SIFT (http://sift.jcvi.org), PolyPhen-2 (http://genetics.bwh. harvard.edu/pph2) and Mutation Taster (http://www. mutationtaster.org).

\section{Determination of the AAAS mRNA structure with the c.399+ $1 \mathrm{G}>\mathrm{A}$ variant}

One patient harboured a mutant $A A A S$ gene with c. $399+1 G>A$. Subsequent mRNA analysis was performed to test its pathogenicity. Human Splicing Finder (HSF) 3.0 software (http://www.umd.be/HSF3/index. html) was used to predict the potential donor or acceptor site alteration of the altered splice site. Total RNA was isolated from the peripheral blood of the proband, the parents and normal control individuals (Total RNA Kit, TIANGEN BIOTECH, Beijing, China). The forward primer 5'-TGGATCAATCTTCCTGTCCTACAAC-3', covering the first $25 \mathrm{bp}$ of exon 2 , and the reverse primer 5'-TACAGTGAACAGCAGTCGG-3, 46 bp upstream of the end of exon 11, were used to amplify the transcripts of both the wild-type and mutant $A A A S$ genes. The amplification product of normal individuals was predicted to be $919 \mathrm{bp}$. The PCR products were separated by agarose electrophoresis and then extracted from the agarose gel (TIANgel Midi Purification Kit, TIANGEN BIOTECH, Beijing, China). The diversity of transcripts was verified by Sanger sequencing.

\section{Genotype-phenotype correlation in children with CAH}

$\mathrm{CAH}$ patient genotypes were categorized into 5 groups as previously described [27, 28]. Briefly, group 0 included null variants on both alleles; group A included homozygotes for the I2G variant or compound heterozygotes for the $\mathrm{I} 2 \mathrm{G}$ variant and a group 0 variant; group $\mathrm{B}$ included patients who were either homozygous or compound heterozygous for the p.I173N variant with group 0 or A variants; group $\mathrm{C}$ included patients who were either homozygous or compound heterozygous for the p.P31L or p.V281L variants with group 0 , A or B variants; and group D included unidentified variants and new variants. The genotype-phenotype correlation was assessed in the patients with both genetic and initial clinical information. The positive predictive value (PPV) was calculated as the percentage of patients with the predicted phenotype. The predicted phenotypes were salt wasting (SW) for groups 0 and $\mathrm{A}$, simple virilization (SV) for group $\mathrm{B}$, and nonclassic (NC) for group $\mathrm{C}$.

\section{Statistical analysis}

SPSS Statistics (19.0) software was used for statistical analysis. The data are expressed as the median and inter quartile range (IQR) due to non-normal distributions. Comparisons between groups were performed using the Mann-Whitney U test without the missing data, and differences were regarded as significant if $\mathrm{p}<0.05$.

\section{Results}

Clinical characteristics of children with $\mathrm{CAH}$

Among the 70 children, 84.3\% (59/70) had $\mathrm{CAH}$, and $15.7 \%(11 / 70)$ had uncharacterized PAI. The sex ratio was almost equal among $\mathrm{CAH}$ patients (male 29, female $30)$, and a male predominance $(81.8 \%, 9 / 11)$ was found for uncharacterized PAI, as 4 of the male patients had X-linked conditions. Among the $59 \mathrm{CAH}$ patients, SW, SV and NC patients accounted for $66.1 \%$ (39/59), 30.5\% $(18 / 59)$, and $3.4 \%(2 / 59)$ of the samples, respectively. A PGS score $\geq 3$ was found in $93.8 \%(15 / 16)$ of female with SW and $38.5 \%(5 / 13)$ of female with SV (Additional file 5: Table S2). TES and 17-OHP levels were significantly higher in children with SW than in children with SV $(p=0.018$ and $p=0.034$, respectively). Among SW patients, 17-OHP and cortisol levels in females were significantly higher than those in males $(p=0.003$ and $\mathrm{p}=0.033$, respectively).Among female patents, the 17-OHP, cortisol, dehydroepiandrosterone (DHEAS) and TES levels in SW patients were significantly higher 
than those in SV patients $(\mathrm{p}=0.004, \mathrm{p}=0.005, \mathrm{p}=0.042$, $\mathrm{p}=0.008$, respectively) (Fig. 1).

\section{Mutation spectra in the CYP21A2 gene and the genotype- phenotype correlation in 21-OHD patients}

Combined Sanger sequencing and MLPA tests yielded 91.5\% positive (54/59) variant findings. The most common variants were c.293-13C > G (31.3\%), Del (18.6\%), p.I173N (17.0\%), E3 $\Delta 8$ (5.1\%), p.R483PfsX58 (4.2\%) and p.R357W (3.4\%) (Table 1). Two novel variants, namely, c.833dupT (NC_000006.1: g.32007876dupT; NM_000500.9: c.833dupT, reference protein NP_000491: p.279GfsX17) and c.651+2T > G (NC_000006.1: g.32007486T > G; NM_000500.9, c.651 + 2T > G, reference protein NP_000491: p.?), were found in two patients (Additional file 2: Fig. S2). The variant c.833dupT in exon 7 of the CYP21A2 gene was found in an SV patient with the p.I173N variant on the other allele. The splicing variant c. $651+2 \mathrm{~T}>\mathrm{G}$ at the end of exon 5 of the CYP21A2 gene was found in an SW patient with the c.293-13C > G variant on the other allele (Table 2). The protein was predicted to be p.(184D_217Rdel). Complete concordance was observed only in group 0 , while the concordance values were $83.3 \%$ and $84.6 \%$ for groups $\mathrm{A}$ and $\mathrm{B}$, respectively. Two SW patients in group D with only one pathogenic allele presented with elevated 17-OHP, growth retardation, hyperkalaemia, hyponatremia and adrenal hyperplasia. The other two SW patients in group $D$ with the same presentations had no pathogenic variants in the CYP21A2 gene. All the above patients refused to undergo further genetic examination. One NC patient in group D who developed increased 17-OHP and dehydroepiandrosterone with mild pigmentation and bilateral adrenal hyperplasia had a monoallelic variant (Additional file 6: Table S3).

\section{Mutation spectra and the genotype-phenotype correlation in children with uncharacterized PAI}

Highly diverse genetic defects were detected in $72.7 \%(8 / 11)$ of probands from 7 families, and five novel variants were detected in five patients, including 2 in the NROB1 gene (NC_000023.1:

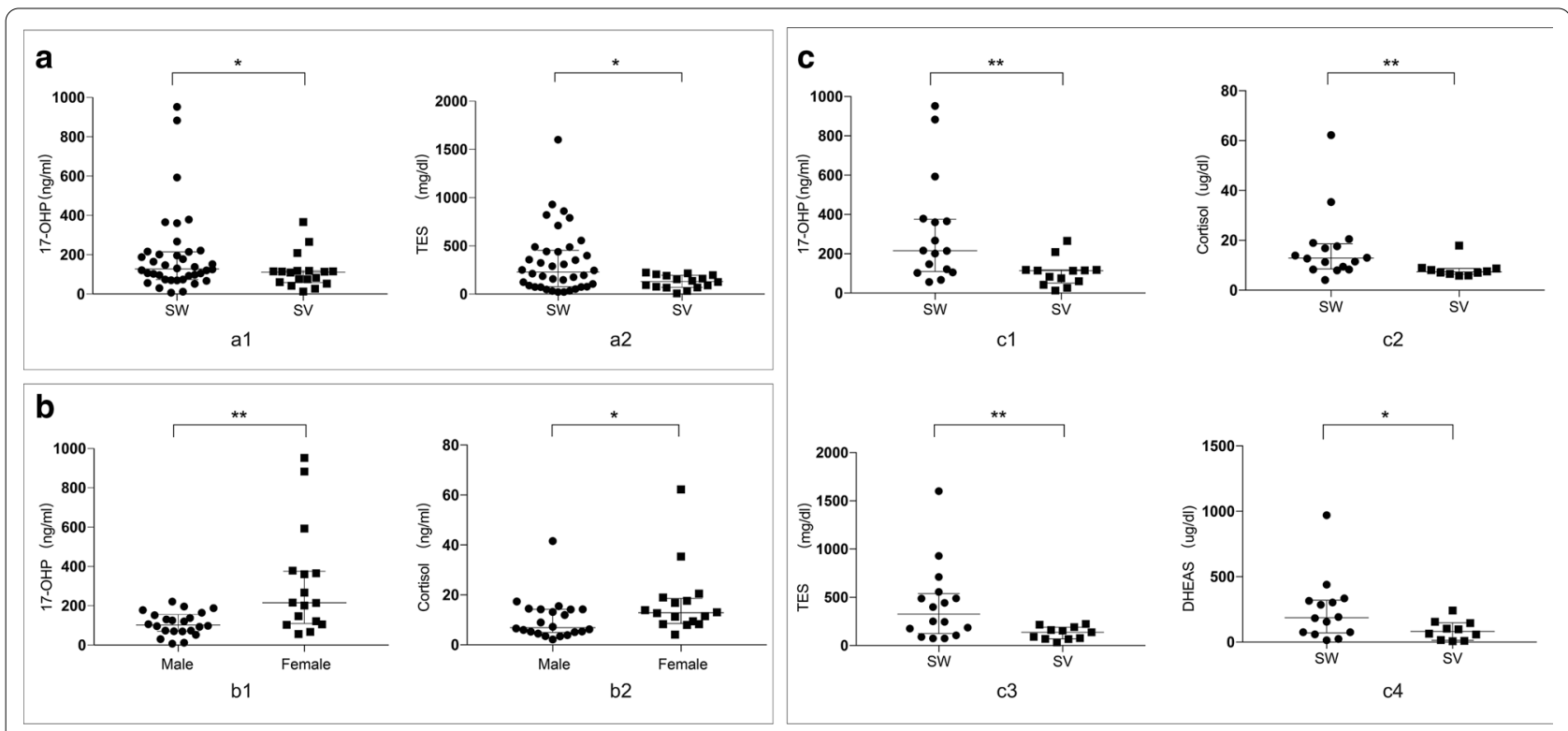

Fig. 1 Differences in relevant serum hormones in CAH patients. The data are expressed as the medians (IQRs) due to non-normal distributions. Comparisons between groups were performed using the Mann-Whitney $U$ test. The 17-OHP level and the serum TES level were significantly higher in SW patients than in SV patients [a1: SW $127.93 \mathrm{ng} / \mathrm{ml}(141.08 \mathrm{ng} / \mathrm{ml}), \mathrm{n}=38 ; \mathrm{SV} 96.21 \mathrm{ng} / \mathrm{ml}(78.00 \mathrm{ng} / \mathrm{ml}), \mathrm{n}=18 ; \mathrm{p}=0.018$. a2: SW 228.90 ng/ dl $(376.90 \mathrm{ng} / \mathrm{dl}), \mathrm{n}=38 ; \mathrm{SV} 131.64 \mathrm{ng} / \mathrm{dl}(125.51 \mathrm{ng} / \mathrm{dl}), \mathrm{n}=16 ; \mathrm{p}=0.034]$. In SW patients, females had significantly higher serum 17-OHP levels [b1: female $215.36 \mathrm{ng} / \mathrm{ml}(265.48 \mathrm{ng} / \mathrm{ml}), \mathrm{n}=16$; male $101.93 \mathrm{ng} / \mathrm{ml}(84.81 \mathrm{ng} / \mathrm{ml}), \mathrm{n}=22 ; \mathrm{p}=0.003$ ] and cortisol levels [b2: female $12.88 \mu \mathrm{g} / \mathrm{dl}$ $(10.05 \mu \mathrm{g} / \mathrm{dl}), \mathrm{n}=16$; male $6.88 \mu \mathrm{g} / \mathrm{dl}(9.27 \mu \mathrm{g} / \mathrm{dl}) \mathrm{n}=22 ; \mathrm{p}=0.033$ ]. In female children, the SW group had increased 17-OHP [c1: SW 215.36 ng/ml $(265.48 \mathrm{ng} / \mathrm{ml}), \mathrm{n}=16 ; \mathrm{SV} 113.63 \mathrm{ng} / \mathrm{ml}(83.39 \mathrm{ng} / \mathrm{ml}), \mathrm{n}=13 ; \mathrm{p}=0.004]$, cortisol [c2: SW $12.88 \mu \mathrm{g} / \mathrm{dl}(10.05 \mu \mathrm{g} / \mathrm{dl}), \mathrm{n}=16 ; \mathrm{SV} 7.35 \mu \mathrm{g} / \mathrm{dl}(2.37 \mu \mathrm{g} /$ $d l), n=10 ; p=0.005]$, TES [c3: SW $325.40 \mathrm{ng} / \mathrm{dl}(415.44 \mathrm{ng} / \mathrm{dl}), \mathrm{n}=16 ;$ SV $138.27 \mathrm{ng} / \mathrm{dl}(122.43 \mathrm{ng} / \mathrm{dl}), \mathrm{n}=11 ; \mathrm{p}=0.008$ ] and DHEAS [c4: SW $187.45 \mu \mathrm{g} / \mathrm{dl}(248.88 \mu \mathrm{g} / \mathrm{dl}), \mathrm{n}=14 ; \mathrm{SV} 81.35 \mu \mathrm{g} / \mathrm{dl}(133.63 \mu \mathrm{g} / \mathrm{dl}), \mathrm{n}=10 ; \mathrm{p}=0.042]$ levels. The initial serum levels of $17-O H P$ in one SW male patient, cortisol in three SV female patients, TES in one SW male patient and two SV female patients, and DHEAS in two SW female patients and three SV female patients were not included due to inconsistent testing methods. Hormone normal ranges ACTH $<46 \mathrm{pg} / \mathrm{ml}$, cortisol 5-25 $\mu \mathrm{g} / \mathrm{dl}$, 17-OHP1 month-1 year $1.06-40.41 \mathrm{ng} / \mathrm{ml}, 1$ year-13 years $0.07-1.53 \mathrm{ng} / \mathrm{ml}$, TES female 0-31 ng/dl, male 0-6 years 3-32 ng/dl, 7-12 years 3-68 ng/dl, DHEAS $35-430 \mu \mathrm{g} / \mathrm{dl}$ 


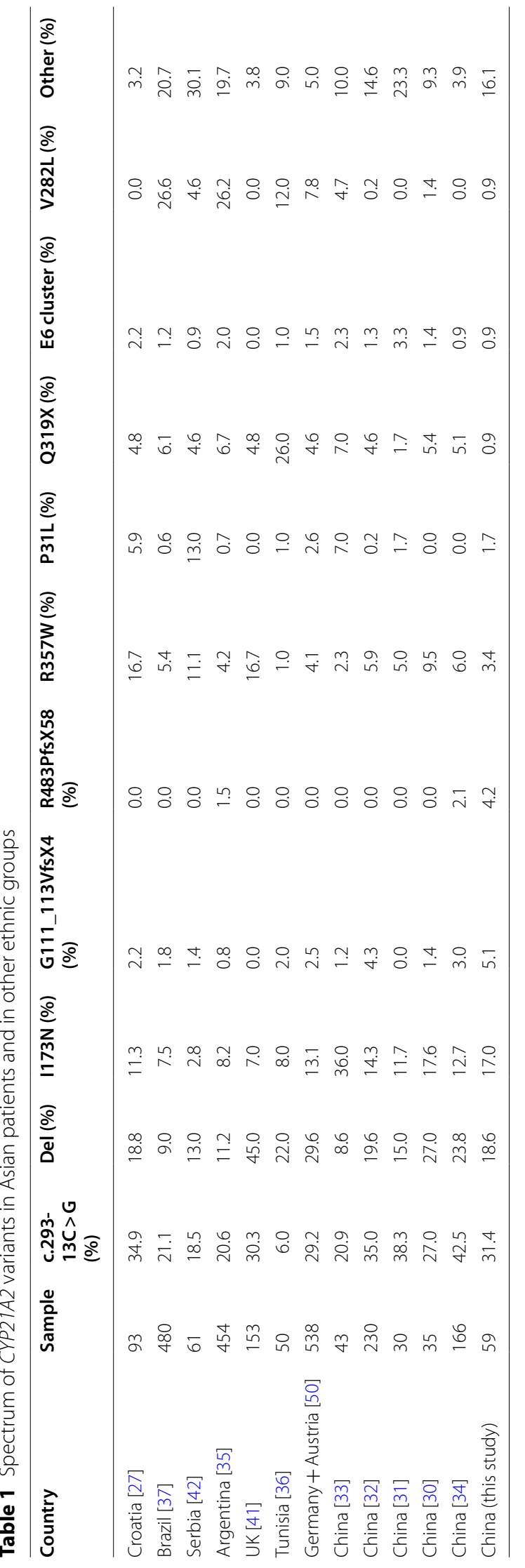


Table 2 Genotype-phenotype correlations in CAH patients

\begin{tabular}{|c|c|c|c|c|c|c|}
\hline \multirow[t]{2}{*}{ Group } & \multirow[t]{2}{*}{ Allele 1} & \multirow[t]{2}{*}{ Allele 2} & \multicolumn{3}{|c|}{ Phenotype } & \multirow{2}{*}{$\begin{array}{l}\text { Positive predictive value for } \\
\text { the predicted phenotype } \\
\text { (\%) }\end{array}$} \\
\hline & & & SW & SV & $\mathrm{NC}$ & \\
\hline \multirow[t]{8}{*}{ Group 0} & Del & Del & 5 & 0 & 0 & \multirow[t]{8}{*}{$100 \%$} \\
\hline & Del & R483PfsX58 & 1 & 0 & 0 & \\
\hline & Del & R357W & 1 & 0 & 0 & \\
\hline & Del & L308FfsX5-Q319X-R357W & 1 & 0 & 0 & \\
\hline & Del & P31L-c.293-13C> G- E3 $\Delta 8$ & 1 & 0 & 0 & \\
\hline & E3 $\triangle 8-Q 319 X$ & c.293-13C> G- Q319X & 1 & 0 & 0 & \\
\hline & Q319X & L308FfsX5- Q319X & 1 & 0 & 0 & \\
\hline & R357W & $\mathrm{E} 3 \triangle 8$ & 1 & 0 & 0 & \\
\hline \multirow[t]{9}{*}{ Group A } & c. $293-13 C>G$ & c. $293-13 C>G$ & 6 & 2 & 0 & \multirow[t]{9}{*}{$83.3 \%$} \\
\hline & c. $293-13 C>$ G & Del & 5 & 0 & 0 & \\
\hline & c.293-13C> G & $\mathrm{E} 3 \triangle 8$ & 2 & 1 & 0 & \\
\hline & c. $293-13 C>G$ & R357W & 2 & 0 & 0 & \\
\hline & c. $293-13 C>$ G & R483PfsX58 & 2 & 0 & 0 & \\
\hline & c. $293-13 C>$ G & E6 cluster & 1 & 0 & 0 & \\
\hline & c. $293-13 C>$ G & c. $293-13 C>$ G- E3 $\triangle 8$ & 1 & 0 & 0 & \\
\hline & c. $293-13 C>$ G- E3 $\triangle 8$ & G292S & 0 & 1 & 0 & \\
\hline & c. $293-13 C>G$ & c. $1223-1 \mathrm{G}>\mathrm{A}$ & 1 & 0 & 0 & \\
\hline \multirow[t]{6}{*}{ Group B } & I173N & I173N & 0 & 5 & 0 & \multirow[t]{6}{*}{$84.6 \%$} \\
\hline & $1173 \mathrm{~N}$ & Del & 0 & 2 & 0 & \\
\hline & $1173 \mathrm{~N}$ & c. $293-13 C>G$ & 1 & 1 & 0 & \\
\hline & $1173 \mathrm{~N}$ & $\mathrm{E} 3 \Delta 8$ & 0 & 2 & 0 & \\
\hline & $1173 N$ & R483PfsX58 & 0 & 1 & 0 & \\
\hline & $1173 \mathrm{~N}$ & L308FfsX6 & 1 & 0 & 0 & \\
\hline \multirow[t]{3}{*}{ Group C } & V282L & $1173 \mathrm{~N}$ & 0 & 0 & 1 & \multirow[t]{3}{*}{ Not applicable ${ }^{a}$} \\
\hline & P31L & Del & 0 & 1 & 0 & \\
\hline & P31L & L308FfsX6 & 0 & 1 & 0 & \\
\hline \multirow[t]{6}{*}{ Group D } & p.279GfsX17 & $1173 \mathrm{~N}$ & 0 & 1 & 0 & \multirow[t]{7}{*}{ Not applicable ${ }^{b}$} \\
\hline & c. $651+2 T>G$ & c. $293-13 C>G$ & 1 & 0 & 0 & \\
\hline & V305M & No pathologic mutations detected & 0 & 0 & 1 & \\
\hline & c. $293-13 C>G$ & No pathologic mutations detected & 1 & 0 & 0 & \\
\hline & R483PfsX58 & No pathologic mutations detected & 1 & 0 & 0 & \\
\hline & $\begin{array}{l}\text { No pathologic mutations } \\
\text { detected }\end{array}$ & No pathologic mutations detected & 2 & 0 & 0 & \\
\hline Total & 39 & 18 & 2 & & & \\
\hline
\end{tabular}

Del large fragment deletion, E3 $\triangle 8$ c.331_339delGAGACTAC, E6 cluster c. [7010T > A;713T > A;719T > A], p. [1237N; V238E; M240K]

${ }^{a}$ The positive predictive value for the expected phenotype was not calculated due to the small sample size

${ }^{b}$ The positive predictive value for the expected phenotype was not calculated because] enzyme activity was unable to predict novel mutations

g.30327156-30327157CG > GA; NM_000475.5, c.323324 CG > GA, reference protein NP_000466: p.S108X and NC_000023.1: g.30322873-30322876delCTCA; NM_000475.5, c.1231_1234delCTCA, reference protein NP_000466:p.L411Vfs*6), 2 in the $A A A S$ gene (NC_000012.1: g.53709118G > A; NM_015665.6, c.399+1G > A, reference protein NP_056480: p.? and NC_000012.1: g.53714350delT; NM_015665.6: c.250delT, reference protein NP_056480: p.W84Gfs*10) and 1 in the NNT gene (NC_000005.1: g.43656054delT; NM_182977.3, c.2274delT, reference protein NP_036475: p.I758Mfs*10) (Table 3, Additional file 3: Fig. S3). Case 1 (mutant $A B C D 1$ gene) showed elevated very longchain fatty acid levels. Case 2 (IL1RAP-NROB1-GK deletion, Xp21.2-21.3) presented with undetectable adrenal glands, increased triglyceride levels, hypothyroidism and cryptorchidism, in addition to typical AI and mineralocorticoid deficiency. Among the four patients with 


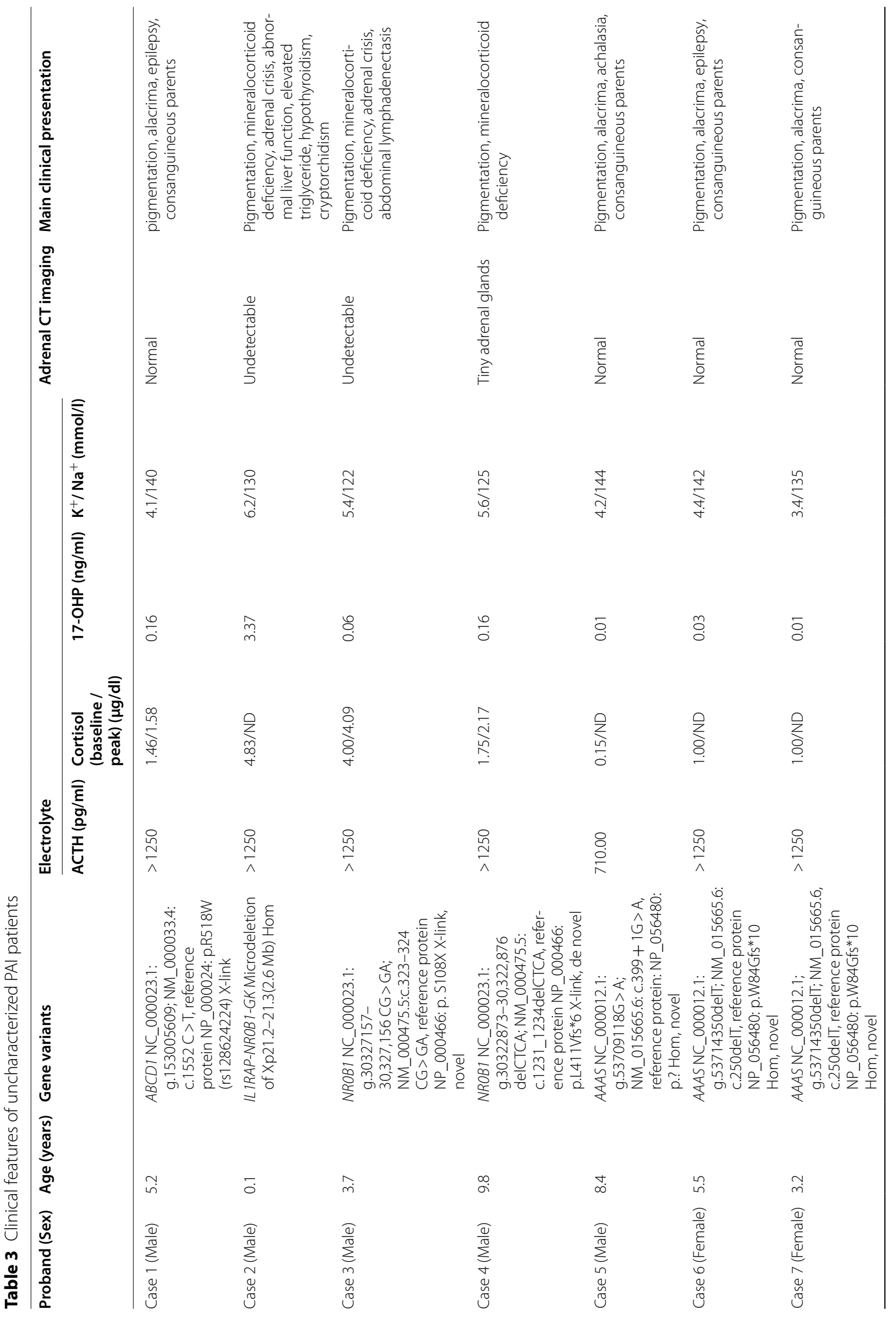




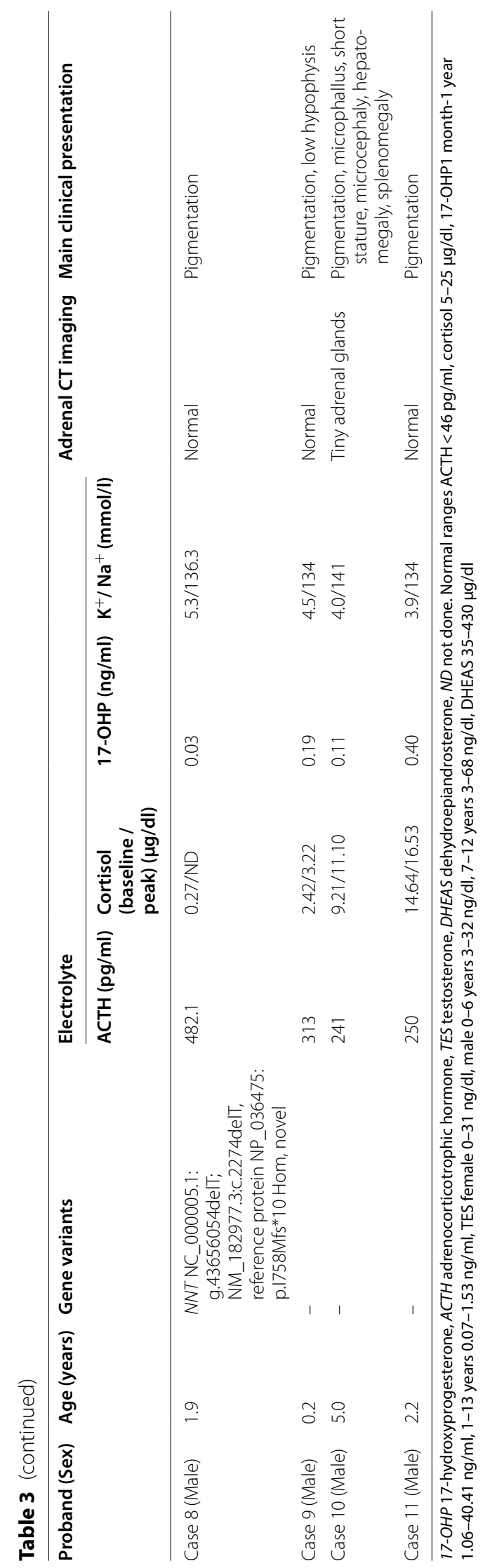


reduced adrenal gland size, $75 \%$ (3/4; cases 2,3 , and 4$)$ harboured NROB1 gene pathogenic variants. Cases 5, 6 and 7 (mutant $A A A S$ gene) had alacrima with or without achalasia and/or neurological symptoms and were all offspring of consanguineous parents. Case 8 (mutant NNT gene) presented no other features in addition to PAI (Table 3).

\section{Pathogenicity analysis of the novel splicing variant c.399+ 1G > A}

Case 5 (Table 3) harboured a novel variant c. $399+1 \mathrm{G}>\mathrm{A}$ at the splicing juncture site at the end of exon 4 in the $A A A S$ gene, which was predicted to affect splicing, as the wild-type motif "TCTgtaagt" was changed to "TCTataagt" without uncovering a cryptic splice site. Agarose electrophoresis of the cDNA from the proband, the parents and a healthy control demonstrated that the parents had two bands: one was a higher-molecular-weight band of the same size as that of the normal control individual, and the other was a lower-molecular-weight band of the same size as that of the patient. Sanger sequencing confirmed the exon 4 skipping in the lower-molecular-weight molecular band, and the protein was predicted to be truncated (Fig. 2).

\section{Discussion}

In the present study, we recruited 70 infants and children with PAI and sequentially performed CYP21A2 gene Sanger sequencing, MLPA testing and biochemical analysis plus detailed clinical examinations and found an overall $84.3 \%(59 / 70)$ diagnostic rate for $\mathrm{CAH}$, with $91.5 \%$ (54/59) of CAH patients showing positive genetic findings. Excluding $\mathrm{CAH}$, for uncharacterized PAI, we found that $72.7 \%(8 / 11)$ of the cases had positive genetic findings by WES and Array-CGH, which is lower than the rate reported in a previous review by Guran et al. (81\%) $[19,29]$. Including $\mathrm{CAH}$, a total of $88.6 \%(62 / 70)$ of the children were determined to have a positive genetic test, which is lower than the $94.2 \%$ positivity rate detected by Perry et al. [2].

Among our 21-OHD CAH patients, the most prevalent $C Y P 21 A 2$ variants were c.293-13C > G (31.4\%), Del (18.6\%), p.I173N (17.0\%), E3 $\Delta 8$ (5.1\%), p.R483PfsX58 (4.2\%) and p.R357W (3.4\%). The first three variants, namely, c.293-13C>G, Del and p.I173N, were consistent with the most frequent variants in the Asian population [30-34]; however, our data showed higher E3 $\Delta 8$ and p.R483PfsX58 variant prevalence rates and a lower p.R357W variant prevalence. Ethnicity-based differences were evident among different studies; the frequencies of p.P31L and p.V282L were $1.7 \%$ and $0.9 \%$ in our study, respectively, and while the p.V282L variant had a dramatically high frequency in Argentina and Brazil [35-37], the p.P31L variant was frequent in Serbia [38] (Table 1). Thus, the genetic background of 21-OHD differs by ethnicity.

Novel variants, namely, c.651 $+2 \mathrm{~T}>\mathrm{G}$ and c.833dupT, were found in the CYP21A2 gene in two children (Table 2), and these variants were predicted to be damaging. Variant c. $651+2 \mathrm{~T}>\mathrm{G}$ located at the end of exon 5 was predicted to alter the wild-type donor site and most likely lead to whole exon 5 skipping, which would result in the loss of 184-217 amino acid residues. With 9 highly conserved residues [39], these residues are essential to construct important functional domains, such as steroid-binding sites (residues 203-207) and large hydrophobic areas (residues 211-218). This splicing site variant likely impairs enzyme activity, because the proband displayed the SW phenotype. The other novel variant, c.833dupT, most likely causes complete loss of enzyme activity, because another comparable frameshift variant, c.923dupT (p.L308FfsX6), which retains more amino acid residues, causes complete loss of enzyme activity [40]. However, more functional studies are required to confirm the exact impact of the novel variants on enzyme activity in the future.

In our research, SW females had higher PGS scores than SV females, as reported by previous studies [41, 42], and the reason may be the higher 17-OHP and TES levels discovered in SW patients (Fig. 1). Interestingly, compared with males, females had higher serum 17-OHP and cortisol levels in both the SW and SV groups, which is consistent with another study [32]. Regarding the genotype-phenotype correlation, the PPV for group 0 was $100 \%$, which is higher than those in most similar studies, while the PPVs in group A (82.6\%) and group B (84.6\%) were in accordance with those in previous studies $[27,32$, $35,37,38]$. Surprisingly, we found that $8.5 \%(5 / 59)$ of the patients clinically presented with the SW $(n=4)$ and NC $(\mathrm{n}=1)$ phenotypes without biallelic variants (Additional file 6: Table S3). Studies have reported that monoallelic variants and absent variants accounted for $2.2 \%$ to $24 \%$ of enrolled children [27, 33, 36-38, 43]. The aetiology is unknown. We deduced that an amplification allele dropout effect may occur due to the high similarity between the CYP21A1P and CYP21A2 genes. Additionally, the $C Y P 21 A 2$ gene promoter region and other intronic variants that have not been analysed in studies may also reduce transcriptional activity [21].

In our uncharacterized PAI patients, we detected a total of 7 pathogenic variants, including one chromosome microdeletion and 5 novel variants in the NROB1, $A A A S, N N T$ and $A B C D 1$ genes. The NROB1 gene is the most frequent gene responsible for X-linked AHC in males (Table 4). The absence of NROB1 is proposed to cause progenitor cells to prematurely differentiate into 

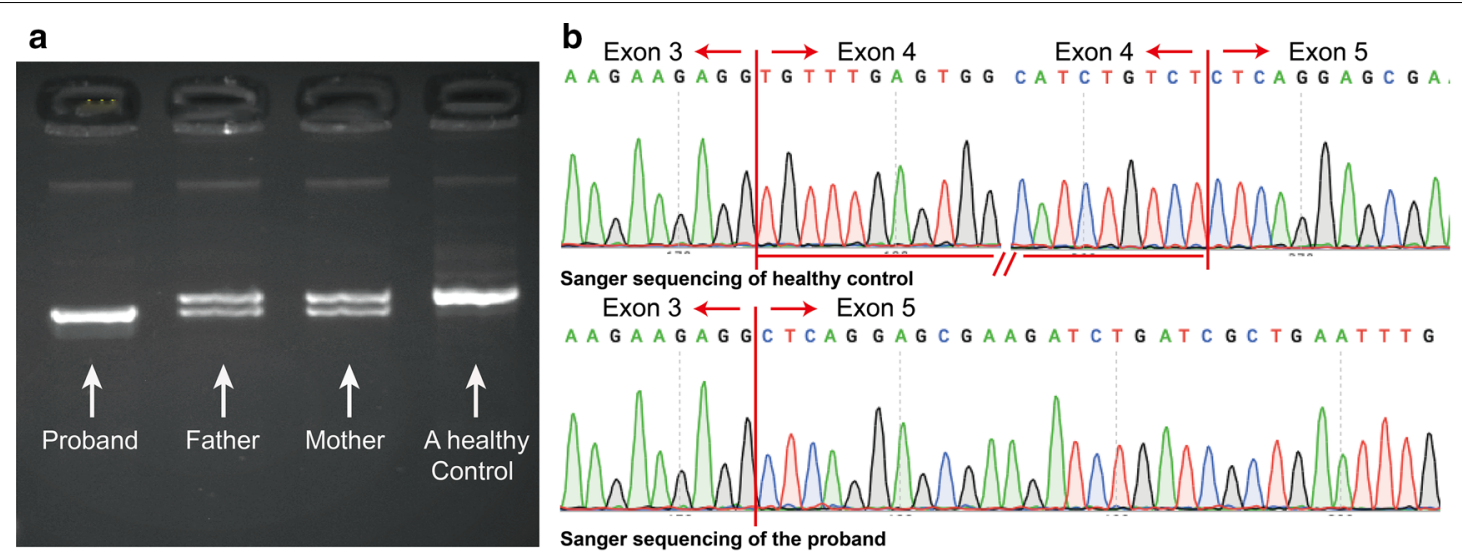

Sanger sequencing of healthy control

$$
\text { Exon } 3 \longleftarrow \text { Exon } 5
$$

A A G A A A G G TCAG GAGCGAAGATCTGATCGCTGAATTTG

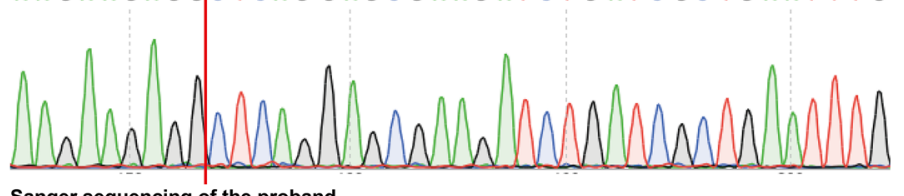

Sanger sequencing of the proband
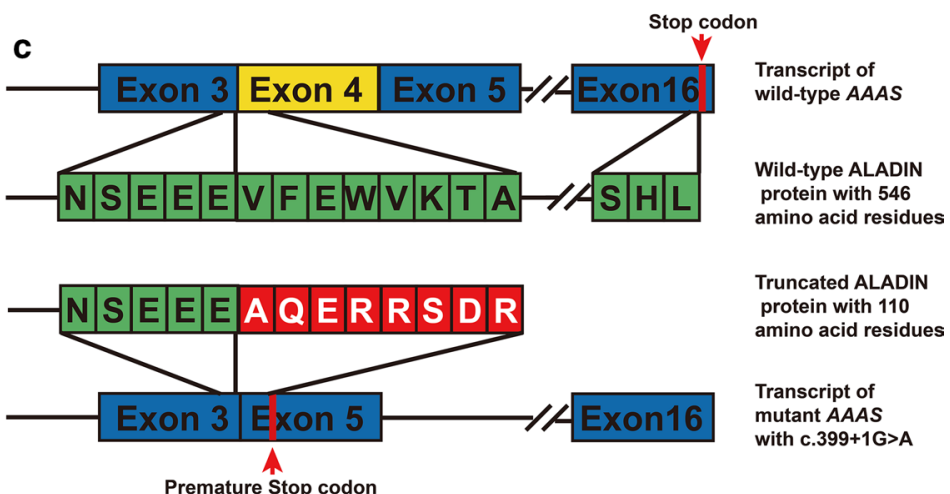

Truncated ALADIN protein with 110 amino acid residues

Transcript of mutant AAAS with $c .399+1 G>A$

Premature Stop codon

Fig. 2 Transcripts of wild-type and mutant (c.399+1G>A) AAAS. a Agarose gel electrophoresis of the proband, the parents and healthy controls. $\mathbf{b}$ Sequencing of the purified band. The front band lacks exon 4. c Transcripts and translation of wild-type AAAS and mutant AAAS. The exon 4 skipping resulted in a premature stop codon and truncated ALADIN protein

steroidogenic cells without adequate maturity $[44,45]$. We found two patients with one novel variant (c.323324 CG>GA and c.1231_1234delCTCA) and one infant with an NROB1 deletion that manifested as PAI, mineralocorticoid deficiency and diminished adrenal glands; however, no hypogonadotropic hypogonadism was noted due to the patient's young age. We also found two novel homozygous pathologic variants in the $A A A S$ gene $($ c.399+1G $>$ A and c.250delT) in 3 patients (Table 3, cases 6,7 , and 8) from 2 families, and both parents were consanguineous. Alacrima and AI were found in all three patients; however, achalasia was observed in only an 8-year-old boy, manifesting as swallowing difficulties. The other two sisters shared the same genotype with different phenotypes. These results suggest that careful estimation should be performed in every child with PAI with alacrima or achalasia. The $A B C D 1$ gene is another causative gene that is often observed in male patients and results in X-linked ALD [45]. The clinical presentation of X-linked ALD is variable, and no phenotype-genotype correlation has been observed [46]. These phenotypes include cerebral, adrenal, spinal cord and peripheral nerve involvement [46]. Fifty percent of affected children ultimately develop adrenomyeloneuropathy within 10 years [47]. Our patients showed clinical PAI, elevated serum long-chain fatty acid levels and normal neurological examination results but had white matter lesions detected by magnetic resonance imaging. We also found a novel pathogenic variant in the NNT gene (c.2274delT). Researchers reported that $53 \%$ of patients with NNT gene variants presented with hyperpigmentation, while 17\% had mineralocorticoid deficiency [48]. Cardiac and thyroid involvement may also exist [49]. Therefore, a close long-term follow-up is still needed, as our patient presented with only hyperpigmentation. Evident genetic defects were not detected in three PAI patients, and we deduced that our current test methods may fail to identify deep intronic variants and epigenetic changes [17-20].

\section{Conclusions}

In conclusion, the genetic causes of PAI in children are very diverse, with a high prevalence of 21-OHD. A total of 7 novel gene variants were detected in the CYP21A2, NROB1, AAAS and NNT genes in our cohort. SW 21-OHD females showed higher PGS scores than SV 


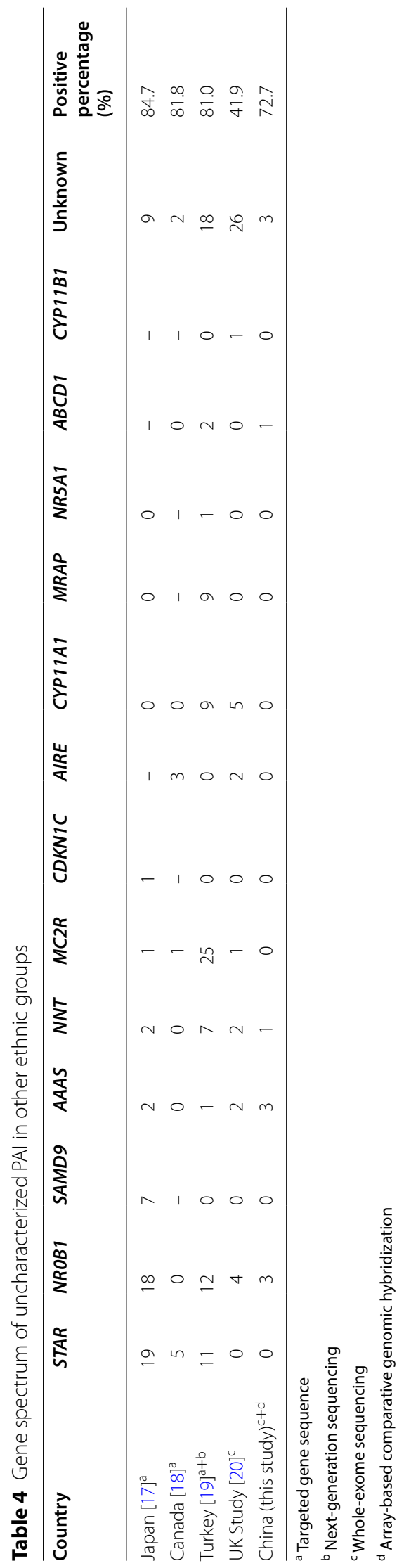


females, which was consistent with the higher levels of 17-OHP and TES. Ethnicity-based differences existed in the genetic variant spectrum of the CYP21A2 gene. Evident genetic variants were not detected in $11.43 \%$ of the PAI patients despite our combined genetic testing protocol, suggesting that testing tools must be improved in future studies.

\begin{abstract}
Abbreviations
PAl: Primary adrenal insufficiency; ACTH: Adrenocorticotrophic hormone; $\mathrm{CAH}$ : Congenital adrenal hyperplasia; PGS: Prader genital scale; 17-OHP: 17-Hydroxyprogesterone; 21-OHD: 21-Hydroxylase deficiency; Array-CGH: Array-based comparative genomic hybridization; WES: Whole-exome sequencing; TES: Testosterone; DHEA-S: Dehydroepiandrosterone sulphate; HSF: Human Splicing Finder; PPV: Positive predictive value; SW: Salt wasting; SV: Simple virilization; NC: Non-classic; MLPA: Multiplex ligation-dependent probe amplification; ALD: Adrenoleukodystrophy; X-linked AHC: X-linked adrenal hypoplasia congenita; Al: Adrenal insufficiency; IQR: Inter quartile range.
\end{abstract}

\section{Supplementary Information}

The online version contains supplementary material available at https://doi. org/10.1186/s12920-021-01021-x.

Additional file 1: Fig. S1. Diagnostic algorithm for PAI patients. For a patient with primary adrenal insufficiency, a high serum level of 17-OHP suggests $C A H$, and he or she was subjected to CYP21A2 sequencing and MLPA. Children with normal or lower 17-OHP levels accompanied by developmental delay, intellectual disability or congenital anomalies underwent Array-GCH examination. WES was performed for the remaining patients.

Additional file 2: Fig. S2. Sanger sequencing of novel variants in the CYP21A2 gene. a c.833dupT. b c.651+2T>G.

Additional file 3: Fig. S3. Variants and Xp21.2 microdeletion in uncharacterized PAI. a c.1552C>T in the ABCD1 gene (case 1, NC_000023.1: g.153005609C>T; NM_000033.4; C.1552 C >T, reference protein NP_000024: p.R518W, rs128624224). b c.323-324CG>GA in the NR0B1 gene (case 3, NC_000023.1: g.30327156-30327157CG>GA; NM_000475.5, c.323-324 CG>GA, reference protein NP_000466: p.S108X). c c.1231_1234delCTCA in the NROB1 gene (case 4, NC_000023.1: g.30322873-30322876delCTCA; NM_000475.5, c.1231_1234delCTCA, reference protein NP_000466: p.L411Vfs*6). d c.399+1G>A in the AAAS gene (case 5, NC_000012.1: g.53709118G >A; NM 015665.6, c.399+1G>A, reference protein NP_056480: p.?). e c.250delT in the AAAS gene (cases 6 and 7, and NC_000012.1: g.53714350delT; NM_015665.6: c.250delT, reference protein NP_056480: p. W84Gfs*10). f c.2274delT in the NNT gene (case 8, NC_000005.1: g.43656054delT; NM_182977.3, c.2274delT, reference protein NP_036475: p.I758Mfs*10).g 2.6M microdeletion on Xp21.2 (case 2). For Sanger sequencing, all sequences were forward sequences except for the patient in case 3 and his parents. The patient case 3 had a de novo variant, and his mother had the wild-type allele of the NROB1 gene. Their sequences were reverse sequences.

Additional file 4: Table S1. PCR primers for CYP21A2 amplification.

Additional file 5: Table S2. PGS of CAH patients.

Additional file 6: Table S3. Variants in CYP21A2 gene.

Additional file 7: Table S4. Clinical features of CAH patients without pathologic biallelic variants.

\section{Acknowledgements}

The authors thank Dr. Wu Bing-Bing and Dr. Yang Lin for their technical assistance with genetic testing. The authors are grateful to all the patients for their invaluable contribution to this study.

\section{Authors' contributions}

FL designed and supervised the study and critically reviewed and revised the manuscript. ZC performed the entire study, collected the data and drafted the manuscript. WL, ZZ1, LX, XL, RY, JN, ZP, MZ, RC, ZZ2, CS, and JW cared for the patients, helped collect data, and reviewed and revised the manuscript. All authors have read and approved the final manuscript.

\section{Funding}

The study was supported by the Children's Hospital of Fudan University (No. EK112520180204). The funding body played no role in the design of the study and collection, analysis, and interpretation of data and in writing the manuscript.

\section{Availability of data and materials}

The datasets in the current study are available in the Mendeley repository (https://github.com/Alice-Izl-CZ/Public-data.git). Relevant genetic polymorphisms have been submitted to NCBI ClinVar (SCV001652698, SCV001652697, SCV001652696, SCV001652695, SCV001652694, SCV001623017). Transcripts data were downloaded from UCSC Genome Brower (http://genome.ucsc. edu/cgi-bin/hgGateway), accession number: NM_000500.9, NM_000033.4, NM_000475.5, NM_015665.6 and NM_182977.3.

\section{Declarations}

\section{Ethics approval and consent to participate}

The study was approved by the Ethics Committee of the Children's Hospital of Fudan University. Permission to access the clinical data used in the research was provided by the Ethics Committee of the Children's Hospital of Fudan University. Written informed consent for the study was obtained from all of the patients' parents. A copy of the consent form is available for review by the Editor of this journal.

\section{Consent for publication}

Written informed consent for the publication of personal and clinical details was obtained from all of the patients' parents. A copy of the consent form is available for review by the Editor of this journal.

\section{Competing interests}

The authors declare that they have no conflicts of interest related to this work.

Received: 17 September 2020 Accepted: 21 June 2021

Published online: 30 June 2021

\section{References}

1. Roucher-Boulez F, Mallet-Motak D, Tardy-Guidollet V, Menassa R, Goursaud C, Plotton I, et al. News about the genetics of congenital primary adrenal insufficiency. Ann Endocrinol (Paris). 2018;79(3):174-81.

2. Perry R, Kecha O, Paquette J, Huot C, Van Vliet G, Deal C. Primary adrenal insufficiency in children: twenty years experience at the Sainte-Justine Hospital. Montreal J Clin Endocrinol Metab. 2005;90(6):3243-50.

3. Guran T. Latest insights on the etiology and management of primary adrenal insufficiency in children. J Clin Res Pediatr Endocrinol. 2017;9(Suppl 2):9-22.

4. Bose HS, Sugawara T, Strauss JR, Miller WL. The pathophysiology and genetics of congenital lipoid adrenal hyperplasia. N Engl J Med. 1996;335(25):1870-8.

5. New MI. Molecular genetics and the characterization of steroid 21-hydroxylase deficiency. Endocr Res. 1986;12(4):505-22.

6. Lin L, Gu WX, Ozisik G, To WS, Owen CJ, Jameson JL, et al. Analysis of DAX1 (NR0B1) and steroidogenic factor-1 (NR5A1) in children and adults with primary adrenal failure: ten years' experience. J Clin Endocrinol Metab. 2006;91(8):3048-54.

7. Arboleda VA, Lee H, Parnaik R, Fleming A, Banerjee A, Ferraz-de-Souza B, et al. Mutations in the PCNA-binding domain of CDKN1C cause IMAGe syndrome. Nat Genet. 2012;44(7):788-92.

8. Narumi S, Amano N, Ishii T, Katsumata N, Muroya K, Adachi M, et al. SAMD9 mutations cause a novel multisystem disorder, MIRAGE 
syndrome, and are associated with loss of chromosome 7. Nat Genet. 2016;48(7):792-7.

9. Weber A, Clark AJ. Mutations of the ACTH receptor gene are only one cause of familial glucocorticoid deficiency. Hum Mol Genet. 1994;3(4):585-8.

10. Metherell LA, Chapple JP, Cooray S, David A, Becker C, Ruschendorf F, et al. Mutations in MRAP, encoding a new interacting partner of the ACTH receptor, cause familial glucocorticoid deficiency type 2. Nat Genet. 2005;37(2):166-70.

11. Handschug K, Sperling S, Yoon SJ, Hennig S, Clark AJ, Huebner A. Triple A syndrome is caused by mutations in AAAS, a new WD-repeat protein gene. Hum Mol Genet. 2001;10(3):283-90.

12. Meimaridou E, Kowalczyk J, Guasti L, Hughes CR, Wagner F, Frommolt $\mathrm{P}$, et al. Mutations in NNT encoding nicotinamide nucleotide transhydrogenase cause familial glucocorticoid deficiency. Nat Genet. 2012;44(7):740-2.

13. Prasad R, Chan LF, Hughes CR, Kaski JP, Kowalczyk JC, Savage MO, et al. Thioredoxin Reductase 2 (TXNRD2) mutation associated with familial glucocorticoid deficiency (FGD). J Clin Endocrinol Metab. 2014;99(8):E1556-63.

14. Mosser J, Lutz Y, Stoeckel ME, Sarde CO, Kretz C, Douar AM, et al. The gene responsible for adrenoleukodystrophy encodes a peroxisomal membrane protein. Hum Mol Genet. 1994;3(2):265-71.

15. Geisbrecht BV, Collins CS, Reuber BE, Gould SJ. Disruption of a PEX1-PEX6 interaction is the most common cause of the neurologic disorders Zellweger syndrome, neonatal adrenoleukodystrophy, and infantile Refsum disease. Proc Natl Acad Sci U S A. 1998;95(15):8630-5.

16. Fasano T, Pisciotta L, Bocchi L, Guardamagna O, Assandro P, Rabacchi C, et al. Lysosomal lipase deficiency: molecular characterization of eleven patients with Wolman or cholesteryl ester storage disease. Mol Genet Metab. 2012:105(3):450-6.

17. Amano N, Narumi S, Hayashi M, Takagi M, Imai K, Nakamura T, et al. Genetic defects in pediatric-onset adrenal insufficiency in Japan. Eur J Endocrinol. 2017;177(2):187-94.

18. Tsai SL, Green J, Metherell LA, Curtis F, Fernandez B, Healey A, et al. Primary adrenocortical insufficiency case series: genetic etiologies more common than expected. Horm Res Paediatr. 2016;85(1):35-42.

19. Guran T, Buonocore F, Saka N, Ozbek MN, Aycan Z, Bereket A, et al. Rare causes of primary adrenal insufficiency: genetic and clinical characterization of a large nationwide cohort. J Clin Endocrinol Metab. 2016;101(1):284-92.

20. Chan LF, Campbell DC, Novoselova TV, Clark AJ, Metherell LA. Wholeexome sequencing in the differential diagnosis of primary adrenal insufficiency in children. Front Endocrinol (Lausanne). 2015;6:113.

21. Narasimhan ML, Khattab A. Genetics of congenital adrenal hyperplasia and genotype-phenotype correlation. Fertil Steril. 2019;111(1):24-9.

22. Eyal O, Levin Y, Oren A, Zung A, Rachmiel M, Landau Z, et al. Adrenal crises in children with adrenal insufficiency: epidemiology and risk factors. Eur J Pediatr. 2019;178(5):731-8.

23. Settas N, Persky R, Faucz FR, Sheanon N, Voutetakis A, Lodish M, et al. SGPL1 deficiency: a rare cause of primary adrenal insufficiency. J Clin Endocrinol Metab. 2019;104(5):1484-90.

24. Bornstein SR, Allolio B, Arlt W, Barthel A, Don-Wauchope A, Hammer GD, et al. Diagnosis and treatment of primary adrenal insufficiency: an endocrine society clinical practice guideline. J Clin Endocrinol Metab. 2016;101(2):364-89.

25. New MI, Lorenzen F, Lerner AJ, Kohn B, Oberfield SE, Pollack MS, et al. Genotyping steroid 21-hydroxylase deficiency: hormonal reference data. J Clin Endocrinol Metab. 1983;57(2):320-6.

26. Speiser PW, Azziz R, Baskin LS, Ghizzoni L, Hensle TW, Merke DP, et al. Congenital adrenal hyperplasia due to steroid 21-hydroxylase deficiency: an Endocrine Society clinical practice guideline. J Clin Endocrinol Metab. 2010;95(9):4133-60.

27. Dumic KK, Grubic Z, Yuen T, Wilson RC, Kusec V, Barisic I, et al. Molecular genetic analysis in 93 patients and 193 family members with classical congenital adrenal hyperplasia due to 21-hydroxylase deficiency in Croatia. J Steroid Biochem Mol Biol. 2017;165(Pt A):51-6.

28. Wedell A, Thilen A, Ritzen EM, Stengler B, Luthman H. Mutational spectrum of the steroid 21-hydroxylase gene in Sweden: implications for genetic diagnosis and association with disease manifestation. J Clin Endocrinol Metab. 1994;78(5):1145-52.
29. Kirkgoz T, Guran T. Primary adrenal insufficiency in children: diagnosis and management. Best Pract Res Clin Endocrinol Metab. 2018;32(4):397-424.

30. Chan AO, But WM, Ng KL, Wong LM, Lam YY, Tiu SC, et al. Molecular analysis of congenital adrenal hyperplasia due to 21-hydroxylase deficiency in Hong Kong Chinese patients. Steroids. 2011;76(10-11):1057-62.

31. Ma D, Chen Y, Sun Y, Yang B, Cheng J, Huang M, et al. Molecular analysis of the CYP21A2 gene in Chinese patients with steroid 21-hydroxylase deficiency. Clin Biochem. 2014;47(6):455-63.

32. Wang $R$, Yu Y, Ye J, Han L, Qiu W, Zhang H, et al. 21-hydroxylase deficiencyinduced congenital adrenal hyperplasia in 230 Chinese patients: genotype-phenotype correlation and identification of nine novel mutations. Steroids. 2016;108:47-55.

33. Zhang B, Lu L, Lu Z. Molecular diagnosis of Chinese patients with 21-hydroxylase deficiency and analysis of genotype-phenotype correlations. J Int Med Res. 2017;45(2):481-92.

34. Su L, Yin X, Cheng J, Cai Y, Wu D, Feng Z, et al. Clinical presentation and mutational spectrum in a series of 166 patients with classical 21-hydroxylase deficiency from South China. Clin Chim Acta. 2018;486:142-50.

35. Marino R, Ramirez P, Galeano J, Perez GN, Rocco C, Ciaccio M, et al. Steroid 21-hydroxylase gene mutational spectrum in 454 Argentinean patients: genotype-phenotype correlation in a large cohort of patients with congenital adrenal hyperplasia. Clin Endocrinol (Oxf). 2011;75(4):427-35.

36. Ben Cl, Riepe FG, Clauser E, Ayedi A, Makni S, Sfar MT, et al. Steroid 21-hydroxylase gene mutational spectrum in 50 Tunisian patients: characterization of three novel polymorphisms. Gene. 2012;507(1):20-6.

37. de Carvalho DF, Miranda MC, Gomes LG, Madureira G, Marcondes JA, Billerbeck AE, et al. Molecular CYP21A2 diagnosis in 480 Brazilian patients with congenital adrenal hyperplasia before newborn screening introduction. Eur J Endocrinol. 2016;175(2):107-16.

38. Milacic I, Barac M, Milenkovic T, Ugrin M, Klaassen K, Skakic A, et al. Molecular genetic study of congenital adrenal hyperplasia in Serbia: novel p.Leu129Pro and p.Ser165Pro CYP21A2 gene mutations. J Endocrinol Invest. 2015;38(11):1199-210.

39. Robins T, Carlsson J, Sunnerhagen M, Wedell A, Persson B. Molecular model of human CYP21 based on mammalian CYP2C5: structural features correlate with clinical severity of mutations causing congenital adrenal hyperplasia. Mol Endocrinol. 2006;20(11):2946-64.

40. White PC, Speiser PW. Congenital adrenal hyperplasia due to 21-hydroxylase deficiency. Endocr Rev. 2000;21 (3):245-91.

41. Krone N, Rose IT, Willis DS, Hodson J, Wild SH, Doherty EJ, et al. Genotypephenotype correlation in 153 adult patients with congenital adrenal hyperplasia due to 21-hydroxylase deficiency: analysis of the United Kingdom Congenital adrenal Hyperplasia Adult Study Executive (CaHASE) cohort. J Clin Endocrinol Metab. 2013;98(2):E346-54.

42. Krone N, Braun A, Roscher AA, Knorr D, Schwarz HP. Predicting phenotype in steroid 21-hydroxylase deficiency? Comprehensive genotyping in 155 unrelated, well defined patients from southern Germany. J Clin Endocrinol Metab. 2000;85(3):1059-65.

43. Xu C, Jia W, Cheng X, Ying H, Chen J, Xu J, et al. Genotype-phenotype correlation study and mutational and hormonal analysis in a Chinese cohort with 21-hydroxylase deficiency. Mol Genet Genomic Med. 2019;7(6):e671.

44. Scheys $\mathrm{JO}$, Heaton $\mathrm{JH}$, Hammer GD. Evidence of adrenal failure in aging Dax1-deficient mice. Endocrinology. 2011:152(9):3430-9.

45. Lalli E, Sassone-Corsi P. DAX-1, an unusual orphan receptor at the crossroads of steroidogenic function and sexual differentiation. Mol Endocrinol. 2003;17(8):1445-53.

46. Kemp S, Berger J, Aubourg P. X-linked adrenoleukodystrophy: clinical, metabolic, genetic and pathophysiological aspects. Biochim Biophys Acta. 2012;1822(9):1465-74.

47. Turk BR, Theda C, Fatemi A, Moser AB. X-linked adrenoleukodystrophy: pathology, pathophysiology, diagnostic testing, newborn screening and therapies. Int J Dev Neurosci. 2020;80(1):52-72.

48. Jazayeri O, Liu X, van Diemen CC, Bakker-van WW, Sikkema-Raddatz B, Sinke RJ, et al. A novel homozygous insertion and review of published mutations in the NNT gene causing familial glucocorticoid deficiency (FGD). Eur J Med Genet. 2015;58(12):642-9.

49. Roucher-Boulez F, Mallet-Motak D, Samara-Boustani D, Jilani H, Ladjouze A, Souchon PF, et al. NNT mutations: a cause of primary adrenal insufficiency, oxidative stress and extra-adrenal defects. Eur J Endocrinol. 2016;175(1):73-84. 
50. Riedl S, Rohl FW, Bonfig W, Bramswig J, Richter-Unruh A, Fricke-Otto $\mathrm{S}$, et al. Genotype/phenotype correlations in 538 congenital adrenal hyperplasia patients from Germany and Austria: discordances in milder genotypes and in screened versus prescreening patients. Endocr Connect. 2019;8(2):86-94.

\section{Publisher's Note}

Springer Nature remains neutral with regard to jurisdictional claims in published maps and institutional affiliations.
Ready to submit your research? Choose BMC and benefit from:

- fast, convenient online submission

- thorough peer review by experienced researchers in your field

- rapid publication on acceptance

- support for research data, including large and complex data types

- gold Open Access which fosters wider collaboration and increased citations

- maximum visibility for your research: over $100 \mathrm{M}$ website views per year

At BMC, research is always in progress.

Learn more biomedcentral.com/submissions 